\title{
El desplazamiento forzado interno en la región del Catatumbo: vulneración masiva de derechos
}

\section{Internal forced displacement in the Catatumbo region: massive vulneration of rights.}

\section{Ana Maria Carrascal Vergel (D)}

Universidad Francisco de Paula Santander amcarrascalv@ufpso.edu.co

\section{Resumen}

El desplazamiento forzado interno es un fenómeno social producto de la violencia, que ha generado miles de víctimas en la Región del Catatumbo Colombiano. Este artículo analiza los derechos que le son vulnerados a las víctimas y la respuesta institucional frente a los mismos. Esto a través de encuestas practicadas a la población desplazada residente en el municipio de Ocaña y proveniente del Catatumbo; de entrevistas realizadas a sus lideres y a las autoridades locales encargadas de garantizarles sus derechos.

Palabras claves: Desplazado, Región del Catatumbo, Colombia, Derechos, Atención a las víctimas.

\section{Abstract}

Forced internal displacement is a social phenomenon caused by violence, which has generated thousands of victims in the Colombian Catatumbo Region. This article analyzes the rights that are violated and the institutional response to them. This, through surveys conducted to the displaced population resident in the municipality of Ocaña and from the Catatumbo; of interviews with their leaders and local authorities in charge of guaranteeing their rights.

Keywords: Displaced, Catatumbo region, Colombia, Rights, Care for victims.

Articulo: Recibido el 2 de septiembre de 2018 y aprobado el 15 de julio de 2019.

\section{Cómo citar este articulo:}

Carrascal Vergel, AM (2019). El desplazamiento forzado interno en la región del Catatumbo: vulneración masiva de derechos. Reflexión Politica 21(42), pp. 94-107. doi: 10.29375/01240781.3467

\section{Introducción}

El desplazamiento forzado interno es un flagelo social que se ha presentado como consecuencia del conflicto armado que padece Colombia (IDMC, 2016). A julio del 2019, el país reporta en el Registro Único de Víctimas más de 8 millones de desplazados, dentro de los cuales más de cien mil campesinos de la Región del Catatumbo se han visto obligados a romper sus lazos sociales, culturales y materiales, huyendo de sus hogares en busca de seguridad y bienestar (CNMH, 2015). Este fenómeno genera una 
vulneración masiva de derechos que ninguna otra situación humanitaria presenta. Los campesinos desplazados del Catatumbo enfrentan condiciones sociales y familiares difíciles que los dejan expuestos al desconocimiento de sus derechos, por parte de los grupos armados ilegales, la población civil y el Estado. Por esta razón se refugian en el municipio de Ocaña, pues este, al parecer, les ofrece mayores oportunidades. Ocaña es reconocida, de manera informal dentro de los habitantes del Catatumbo, como su capital, la ciudad que ofrece empleo, educación y demás necesidades básicas insatisfechas en sus municipios de origen. Bajo esta mirada esperanzadora hacia dicha ciudad, el interés de asentarse en ella se mantiene en la población desplazada, quienes por su cercanía geográfica la escogen como su nuevo lugar de residencia. No obstante, las consecuencias sociales que genera el desplazamiento forzado han obligado a la sociedad a reaccionar ante las inclemencias que viven nuestros nacionales. El desconocimiento de derechos que supone el flagelo del desplazamiento requiere de una protección jurídica tanto nacional como internacional para devolverles su bienestar y la posibilidad de comenzar un proyecto de vida digno. La complejidad que representa la recepción de víctimas del desplazamiento forzado en el municipio de Ocaña despertó el interés en la comunidad académica de conocer la visión de las víctimas, de sus líderes y de las autoridades locales en cuanto a los derechos que consideran les son vulnerados y los mecanismos de protección utilizados.

Este artículo es el resultado de una investigación adelantada en la Universidad Francisco de Paula Santander - Ocaña, por Carrascal Vergel (2018) cuyo objetivo general consistió en "realizar un diagnóstico frente a los derechos vulnerados a la población desplazada residente en el municipio de Ocaña y de la efectividad de los mecanismos jurídicos utilizados para reclamar sus derechos en el ámbito Internacional y Nacional” (p. 11). Para lograr dicho objetivo trabajamos con las víctimas del desplazamiento forzado interno residentes en el municipio de Ocaña y con las autoridades locales encargadas de atender y garantizar sus derechos. Para ello, se realizaron encuestas a víctimas del desplazamiento forzado interno en la región del
Catatumbo. De otra parte, se realizaron entrevistas a sus líderes sociales más representativos y a las autoridades locales encargadas de su atención.

$\mathrm{El}$ artículo se desarrolla en 5 partes. En la primera nos centramos en el marco teórico, en el cual identificamos conceptos claves para la investigación: desplazamiento forzado interno, mecanismos jurídicos de protección y derechos vulnerados. En la segunda contextualizamos el fenómeno del desplazamiento forzado en la Región del Catatumbo, en las causas y consecuencias sociales que generan este flagelo en dicha región del país. En tercer lugar, evaluamos la respuesta institucional frente a la garantía de sus derechos mediante la información extraída de las entrevistas realizadas a sus líderes y a las autoridades locales. En la cuarta, exponemos los resultados de la investigación, haciendo un diagnóstico de los derechos vulnerados y de los mecanismos jurídicos utilizados para su protección. Finalmente, se plantean las conclusiones en las cuales brindamos un aporte académico a la problemática del desplazamiento en el municipio de Ocaña, ya que alertamos a las autoridades sobre el derecho que consideran vulnerado las víctimas de dicho flagelo y sobre las deficiencias en la respuesta institucional para garantizarlo, ante la ausencia de investigaciones previas sobre la materia.

\section{Marco Teórico}

El desplazamiento forzado interno (DFI) es un fenómeno social que se presenta al interior de cada país como consecuencia de situaciones extremas que se padecen en el territorio de un Estado. En Colombia, este flagelo es producto del conflicto armado en el que ha estado inmersa la Fuerza Pública, grupos guerrilleros, paramilitares y las llamadas bandas criminales (Bacrim). Sin embargo, en los últimos tiempos se han producido desplazamientos de personas como consecuencia de las guerras entre guerrillas por los territorios fértiles para los cultivos de coca, principal fuente de financiamiento de estos grupos ilegales (Ortiz R, 2000). La población civil ajena a los intereses en disputa se ha visto inmersa en los efectos de la guerra, siendo sometida a masacres, secuestros, reclutamiento de menores, viviendo en una constante incertidumbre sobre su 
seguridad, lo que los ha llevado a huir buscando una respuesta estatal a la crisis humanitaria que padecen. El Estado colombiano debe responder por la garantía de los derechos humanos vulnerados a la población desplazada, pues son los responsables directos de garantizar los derechos humanos de sus habitantes, derechos vulnerados a la población desplazada al verse obligados a dejar sus hogares por la inseguridad que sus tierras les genera. La región del Catatumbo colombiano ha sido una zona muy apetecida por los grupos ilegales (Jiménez y Soledad, 2007) para su financiamiento a través de la coca, esto debido a su clima tropical y a la ubicación estratégica (Corporación Colectivo de Abogados Luis Carlos Pérez, 2012) que les permite no solo su producción, sino también su comercialización. El DFI supone para sus víctimas la obligación de abandonar sus hogares, sus lugares de arraigo, sus lazos territoriales y deambular por el interior del territorio colombiano en búsqueda de nuevas oportunidades que los aleje de esa violencia que los obligó a huir. Estas víctimas se ven expuestas a una situación de indefensión y de vulnerabilidad extrema que las aleja del disfrute de sus derechos fundamentales y de la atención necesaria para superar esa situación extrema. Debido a ello, el Estado colombiano ha despertado en el diseño de Mecanismos de Protección, a los cuales la población desplazada pueda acudir para reclamar el goce de sus derechos.

- Nos referimos, en primer lugar, a la acción constitucional consagrada en el artículo 86 de la Constitución, la Acción de Tutela. Este mecanismo les permite acceder a la garantía de sus derechos fundamentales, definidos en nuestra constitución y aquellos consagrados en el derecho internacional, y que por vía del bloque de constitucionalidad hacen parte de nuestra carta magna, de conformidad con el artículo 93. Este mecanismo ha sido el más utilizado por dicha población vulnerable. Debido a lo anterior, la Corte Constitucional unificó varios fallos de tutela en la sentencia T-025/2004 y, de esa manera, consolidó su doctrina con relación a los derechos vulnerados a los desplazados y a la obligación de las entidades del Estado de garantizarlos.

- En el ámbito constitucional, del mismo modo, debemos anotar que el Derecho de Petición, consagrado en el artículo 23, ha sido una herramienta utilizada de manera constante por los desplazados internos para presentar peticiones con relación a sus derechos.

- $\mathrm{El}$ primer avance legal para proteger los derechos de la población desplazada se produce en 1997 con la expedición de la Ley 387 de 1997. En dicha ley, se implementaron medidas tendientes a desarrollar tres puntos determinantes en la materia: la prevención, la acción humanitaria de emergencia y el restablecimiento de la población desplazada. Estas tareas son desarrolladas por diversas entidades estatales, las cuales dirigen sus actividades al cumplimiento del Plan Nacional para la Atención Integral de la Población Desplazada por la Violencia, creadas por esta misma ley.

- Con la expedición de la Ley 1448 del 2011, el Estado pretendió diseñar una herramienta legal para todas las víctimas del conflicto armado, haciendo especial distinción en aquellas víctimas del DFI. En su artículo 13 establece que a las víctimas del desplazamiento forzado interno se les ofrecerán medidas de ayuda humanitaria, atención, asistencia y reparación integral de una manera diferencial, teniendo en cuenta el riesgo al que padecen, y la vulneración de sus derechos. Considerar a la población desplazada como una población que requiere una especial atención nos muestra la preocupación institucional de atender la grave situación que padecen. Como consecuencia de ello dentro del Título III de la mencionada Ley, diseñaron un capítulo completo (Cap. III) para la atención a las víctimas del DFI. En dicho capítulo se define a la víctima del DFI en los siguientes términos: toda persona que se ha visto forzada a migrar dentro del territorio nacional, abandonando su localidad de residencia o actividades económicas habituales, porque su vida, su integridad física, su seguridad o libertad personales han sido vulneradas o se encuentran directamente amenazadas, con ocasión de las violaciones a las que se refiere el artículo $3^{\circ}$ de la presente Ley. (Ley 1448, 2011, art. 60)

- Esta ley manifiesta que la atención a las víctimas del desplazamiento forzado debe realizarse de conformidad con lineamientos establecidos por la Ley 387 y la Ley 1448. 
Como se puede evidenciar, existen mecanismos de protección nacionales, tanto constitucionales como legales que han sido diseñados para atender los reclamos de los desplazados con relación a la garantía de sus derechos. Sin embargo, debemos anotar que este flagelo social genera diversas consecuencias sociales y económicas que no solo afectan el interior del país, sino que muchas veces trascienden sus fronteras (Vidal, 2007). Es por ello que, ante la ineficiente atención de sus necesidades por parte de los Estados o ante la solicitud de apoyo por parte de estos a la comunidad internacional (Martín, Rodríguez y Guevara, 2004), la comunidad internacional ha diseñado planes de ayudas al interior de los países que sufren desplazamientos forzados internos. Nos referimos a las normas del Derecho Internacional de los Derechos Humanos que han pretendido regular el Fenómeno del Desplazamiento Forzado Interno. Estas se encuentran contenidas en el Sistema Universal y el Sistema Interamericano de Protección de los Derechos Humanos, en los cuales se consagran derechos que hacen parte de la protección internacional ofrecida a la población desplazada. En el Sistema Universal encontramos la Carta de las Naciones Unidas, el Pacto Internacional de Derechos Civiles y Políticos, y la Declaración Universal de Derechos Humanos; esta última es considerada el punto de partida para el reconocimiento de los derechos humanos a nivel universal (Oraa y Gómez, 2002). No obstante, el principal instrumento normativo en el Derecho Internacional, con relación al Desplazamiento Forzado Interno, son "Los Principios Rectores de los Desplazamientos Internos", documento presentado por la ONU - Organización de Naciones Unidas, el cual se ha convertido en fuente de obligatoria consulta por parte de los Estados cuando pretendan diseñar políticas públicas a favor de la población desplazada, ya que construyeron una concepción universal del desplazamiento forzado interno, de sus consecuencias, de sus necesidades y de la importancia de ser atendidos dichos principios por toda la humanidad (Abrisketa, 2009). En el Sistema Interamericano encontramos la Declaración Americana de Derechos y Deberes del Hombre, la cual, a pesar de tener solo un carácter recomendatorio para los Estados, los derechos allí consagrados son la base para el reconocimiento de los mismos al interior de los Estados Americanos. En tal sentido, Quispe Remón (2009) afirma que "Pese a la naturaleza recomendatoria y no convencional, por no ser un tratado, hoy su contenido refleja derechos humanos de alcance general y crea obligaciones para los Estados de reconocer y garantizar su ejercicio efectivo" (p.155). Contrario a lo anterior, la Convención Americana de Derechos Humanos sí tiene carácter coercitivo para los Estados miembros de la Organización de Estados Americanos, estos deben acatar lo establecido dentro de ella, so pena de ser juzgados por la Corte Interamericana de derechos humanos. Esto en razón a que los Estados son los responsables de garantizar los derechos humanos a sus ciudadanos por ser estos quienes suscriben y ratifican los tratados que los contienen (Londoño, 2007), como es el caso de la Convención Americana. Como consecuencia de ello, los Estados Americanos se convierten en sujetos procesales ante la Corte Interamericana de Derechos Humanos, tal y como ha sucedió con el Estado colombiano, el cual ha sido condenado en varias oportunidades por el flagelo del desplazamiento forzado interno (Caso Masacre de Mapiripán, 2015). Esto ha convertido al Sistema Interamericano de protección de derechos humanos en un mecanismo jurídico internacional que ha permitido a la población desplazada reclamar sus derechos.

Para concluir este marco teórico, definiremos cuáles derechos se consideran vulnerados a la población desplazada. Un derecho es vulnerado cuando es desconocido a su titular; además, quien está en la obligación de garantizarlo se niega a hacerlo contradiciendo los mandatos constitucionales y legales. La primera aproximación a este tema lo encontramos en la sentencia ya mencionada, la T-025/2004, en donde la Corte Constitucional define cuáles son los derechos vulnerados a una persona desplazada: el derecho a la vida en condiciones de dignidad dadas; los derechos de los grupos especialmente protegidos (niños, mujeres cabeza de hogar, discapacitados, y ancianos); el derecho a escoger su lugar de domicilio; los derechos al libre desarrollo de la personalidad, a la libertad de expresión y de asociación; los derechos económicos, sociales y culturales; el derecho a la unidad familiar; el derecho a la salud, en conexidad con el derecho a la vida; el derecho a la integridad personal; el derecho a la seguridad social; derecho a la libertad de circulación por el territorio nacional; el derecho al trabajo; el derecho a una alimentación mínima; el derecho a la educación; el derecho a una vivienda digna; el derecho a la paz; el derecho a la personalidad jurídica; el derecho a la igualdad; 
$\mathrm{y}$, el derecho a recibir en forma urgente un trato preferente Estado.

Adicionalmente, la Ley 1448 definió los derechos de las víctimas del desplazamiento: el derecho a la verdad, el cual supone conocer los motivos y las causas que produjeron el desplazamiento; derecho a la justicia, supone que los causantes del desplazamiento rindan cuentas ante la justicia; derecho a la reparación integral, que comprende medidas de restitución, indemnización, rehabilitación y garantías de no repetición de nuevos desplazamientos; derecho a retornar a su lugares de residencia iniciales; derecho a que les restituyan sus tierras si han sido despojados. Dichos derechos pueden ser reclamados por los desplazados a través de los mecanismos constitucionales (acción de tutela y derecho de petición) o a través de la atención definida en las leyes 387 y 1448, por parte de las entidades estatales.

A pesar de lo anterior, el $63.71 \%$ de las víctimas del desplazamiento forzado interno de la Región del Catatumbo, desconocen los mecanismos para acceder a sus derechos. Solo el 32.64\% ha utilizado un mecanismo de protección. Esto supone que no es suficiente con el diseño de políticas públicas de atención, sino que se hace necesaria la promoción y divulgación de los mismos a través de campañas de socialización aplicadas a la población objeto de atención.

\section{Marco Contextual}

La región del Catatumbo está conformada por varios municipios: Ocaña, El Carmen, Convención, Teorama, San Calixto, Hacarí, La Playa de Belén, El Tarra, Tibú y Sardinata; alberga los resguardos Motilón-Barí y Catalaura, donde habita el Pueblo Barí. Ocaña y Tibú funcionan como puertas de entrada a la región y son paso obligado para acceder a los demás municipios (CNMH, 2018). Tiene una extensión de casi $5.000 \mathrm{~km}$, en donde su principal actividad económica es la agricultura y la minería. Su variedad climática favorece el cultivo de la hoja de coca, convirtiéndose en un territorio apetecido por los grupos al margen de la ley que se disputan este territorio para adelantar cultivos ilícitos (CNMH, 2015). La región del Catatumbo, en su totalidad, ha sido considerada como una de las regiones más olvidadas por el Estado, lo que ha permitido que los grupos armados se apoderen de zonas sin encontrar limitaciones institucionales que obstaculicen el desarrollo de sus intereses. Esto ha puesto a la población civil Catatumbera, a vivir inmersa en una situación de violencia generalizada y a obedecer políticas de guerra diseñadas por quienes tienen el dominio de sus pueblos. La disputa por el territorio ha generado un conflicto interno en dicha región que ha ocasionado el desplazamiento forzado interno de campesinos entre sus municipios; Ocaña es el principal receptor de víctimas del desplazamiento forzado; este municipio se ve obligado a enfrentar las consecuencias socioeconómicas que trae consigo dicha población vulnerable. Además de lo anterior, la erradicación de los cultivos ilícitos ha generado desplazamientos forzados (Sacipa, 2001) ante la alta producción de coca que existe en el Catatumbo. Lo anterior, ha obligado a miles de campesinos a huir de sus hogares, convirtiéndolos en acreedores de una vulneración masiva de derechos, en habitantes sin territorio que buscan un lugar donde se les reconozcan sus derechos fundamentales, los cuales debe garantizar el Estado (Ceballos, 2013). Este flagelo social ha tenido unas características especiales en la Región del Catatumbo, ya que estas víctimas se han convertido en desplazados permanentes al deambular dentro de dicha zona cada vez que los efectos del conflicto los alcanza (CNMH, 2015). El desplazamiento forzado en la región del Catatumbo ha generado en el municipio de Ocaña, una situación humanitaria difícil de atender. Las personas que provienen de dicha región se localizan en las zonas más desfavorecidas del municipio, donde la cobertura de los servicios básicos aún no ha sido suplida por las autoridades locales. Esto supone una revictimización de su condición de víctima, ya que, no solo han padecido las inclemencias del desplazamiento, sino que se exponen a otros factores de violencia en su lugar de acogida. Lo anterior demuestra que el fenómeno del desplazamiento forzado interno ha creado en dicha región una situación de vulnerabilidad extrema permanente ante el abandono y la poca eficiencia en la aplicación de los planes de atención diseñados para garantizar sus derechos.

\section{Respuesta institucional a la víctima del desplazamiento.}

En el municipio de Ocaña se cuenta con varias entidades encargadas de la atención y la garantía de los derechos vulnerados a las víctimas del 
desplazamiento. Dichas entidades operan atendiendo los parámetros establecidos en el Marco Jurídico Nacional, diseñado en favor de la población desplazada. Nos referimos a la Ley 387 de 1997 y a la Ley 1448 del 2011. Con el fin de conocer cómo Ocaña se encuentra preparada para recibir y atender las necesidades derivadas de la situación de desplazamiento, entrevistamos a las autoridades y organismos encargados de su atención.

- Indagamos en la Defensoría del Pueblo Regional Ocaña sobre los derechos que le reclaman los desplazados y los mecanismos que se utilizan para ser garantizados. Las personas provenientes del Catatumbo se centran en el reclamo de la ayuda inmediata, la cual debe ser entregada por el ente territorial, la Alcaldía Municipal. Al presentarse incumplimiento en la entrega, la Defensoría acude al Derecho de Petición y a la Acción de tutela para lograr dicha ayuda.

- La Unidad para las Víctimas, entidad nacional encargada de atenderlas y repararlas hace presencia en el municipio de Ocaña a través de un recurso humano invaluable. Al abordar a uno de sus funcionarios; este nos contextualizó sobre el papel que desarrollan en favor de la población desplazada que se asienta en Ocaña, que en su gran mayoría provienen de la zona del Catatumbo. El trabajo que adelantan con esta población se encuentra focalizado en la reparación integral y en la superación de la condición de vulnerabilidad en la que se encuentra. No solo se encargan de la entrega efectiva de dicha reparación, también de la asesoría permanente para la utilización de la misma en la construcción de proyectos de vida estables y seguros.

- La Personería Municipal, como representante del ministerio público en el ente territorial, nos aseguró que la llegada masiva de desplazados provenientes del municipio de Ocaña ha generado un colapso en su atención y en la garantía efectiva de sus derechos. Esta oficina atiende a esta población, quienes reclaman de sus servicios para declarar su condición de desplazados y para la utilización de las acciones constitucionales para exigir la garantía de sus derechos.

- La Oficina del Enlace Municipal de Víctimas, como su nombre lo indica, es la encargada de atender a la población víctima que se encuentra en el municipio de Ocaña y de velar por el cumplimiento de las funciones de dicho ente territorial con relación a la atención y garantía de los derechos vulnerados. La representante de dicha oficina manifestó que las víctimas que son atendidas, en su mayoría, provienen del Catatumbo por causa del desplazamiento forzado interno. Estas víctimas reclaman en dicha oficina el cumplimiento por parte de la Alcaldía Municipal en la entrega de las ayudas consagradas en la Ley 1448 del 2011. De igual forma, aseguran que la población desplazada acude con frecuencia para exigir la garantía de su derecho a una vivienda.

Estas autoridades coinciden en que existen falencias en la atención de dichas víctimas, puesto que los recursos económicos y humanos son insuficientes ante la masividad de víctimas del Desplazamiento Forzado Interno que recibe el municipio de Ocaña.

\section{Metodologia}

La investigación se adelantó con el objetivo de realizar un diagnóstico de los derechos que les son vulnerados a los desplazados internos de la región del Catatumbo, los mecanismos jurídicos utilizados para garantizarlos y la respuesta institucional existente para el apoyo de esta población en la búsqueda de la garantía de sus derechos en dicha región del país. Para identificar lo anterior realizamos una investigación cualitativa, partiendo de la recolección de información a través de encuestas y entrevistas, y así, construir un diagnóstico sobre los componentes mencionados. De esta manera, se realizaron 383 encuestas a víctimas del DFI, obteniendo una muestra de la población desplazada recibida en el municipio de Ocaña desde el 2005 hasta el 2017 (17.033 desplazados), aplicando un margen de error del 5\%, y un nivel de confianza del 95\%. Dichas encuestas fueron de tipo descriptivo, realizadas vía internet, en las cuales utilizamos preguntas cerradas con el fin de indagar sobre datos puntuales del desplazamiento como el género, año del desplazamiento, municipio del Catatumbo expulsor, derechos vulnerados; además, se realizó una pregunta abierta sobre los mecanismos jurídicos utilizados. Las encuestas fueron aplicadas a estudiantes víctimas del desplazamiento forzado 
de la Universidad Francisco de Paula Santander Ocaña, de acuerdo a la información suministrada por la oficina de admisiones, así como a víctimas del desplazamiento atendidas en la Defensoría del Pueblo Regional Ocaña.

De igual forma, se aplicaron entrevistas a 7 líderes representativos de la población desplazada, quienes nos explicaron el contexto de la problemática que padecen dentro del municipio; del mismo modo, se entrevistaron a 4 autoridades locales encargadas de la atención a los desplazados, Unidad de Víctimas, Defensoría del Pueblo, Enlace
Municipal y Personería Municipal, quienes nos informaron sobre los protocolos de atención que ejecutan en favor de los desplazados que proviene del Catatumbo.

Con la información obtenida de las encuestas construimos gráficas sobre el porcentaje obtenido por cada una de las respuestas brindadas $\mathrm{y}$, de esa manera, realizamos un diagnóstico sobre las mismas. Tal y como puede verse en las siguientes figuras (1-4).

Finalmente, transcribimos las entrevistas realizadas, las cuales se utilizaron para la

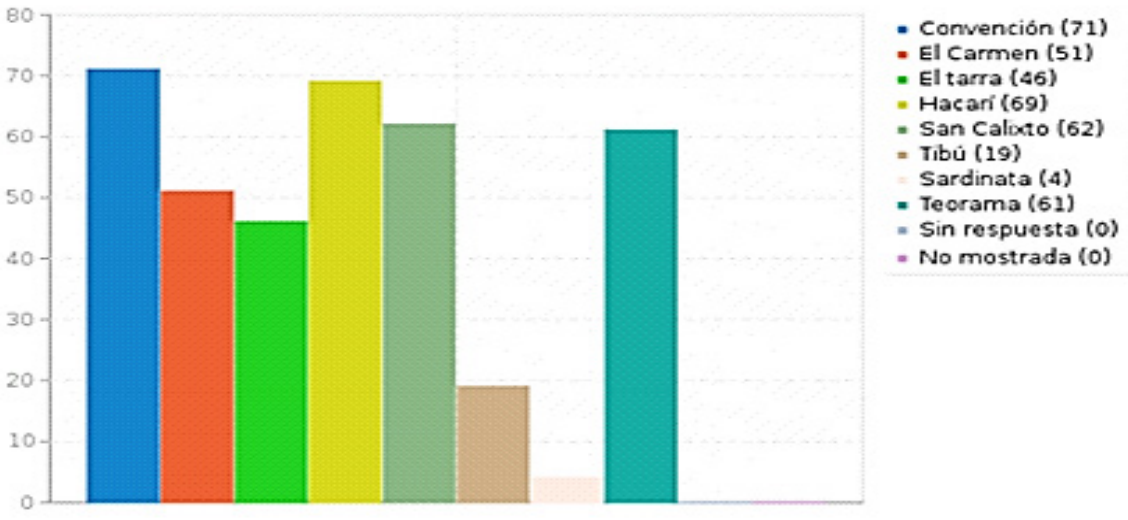

Figura 1. ¿De qué municipio del Catatumbo fue expulsado como víctima del desplazamiento forzado?

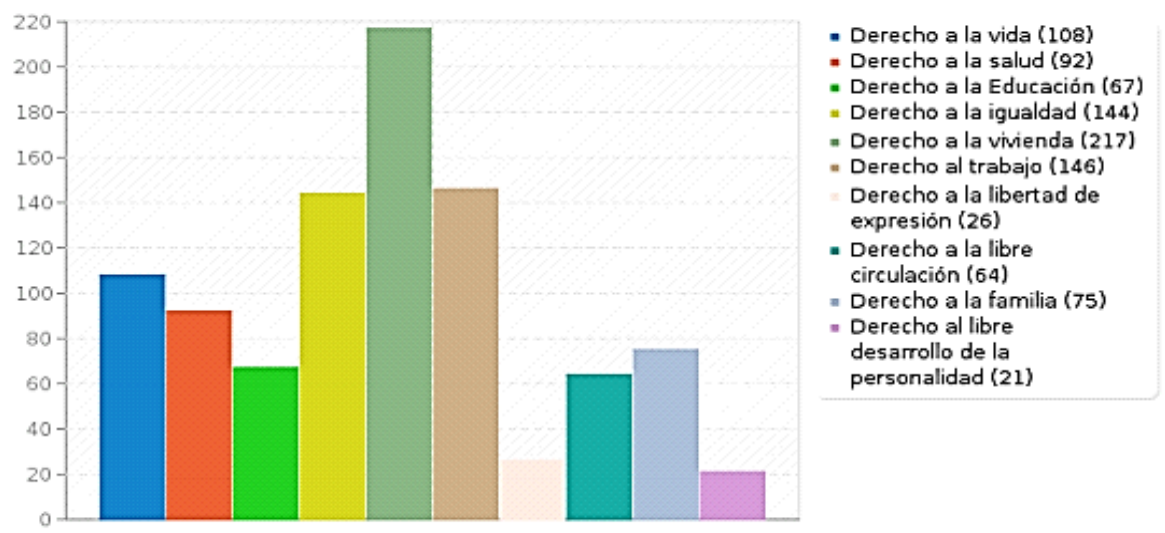

Figura 2. ¿Cuáles derechos le han sido vulnerados con ocasión a su condición de víctima del desplazamiento forzado? 


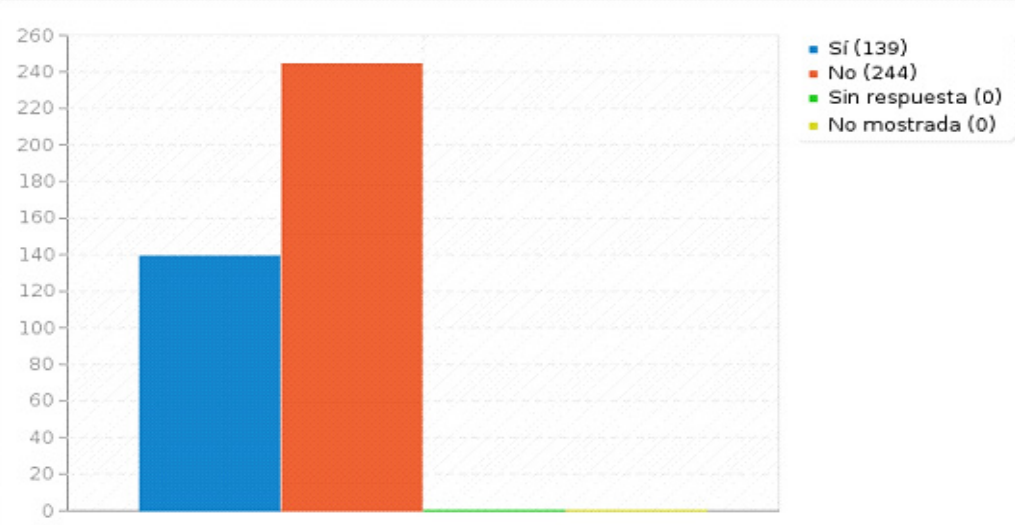

Figura 3. ¿Conoce usted los mecanismos jurídicos de protección de sus derechos como desplazado?

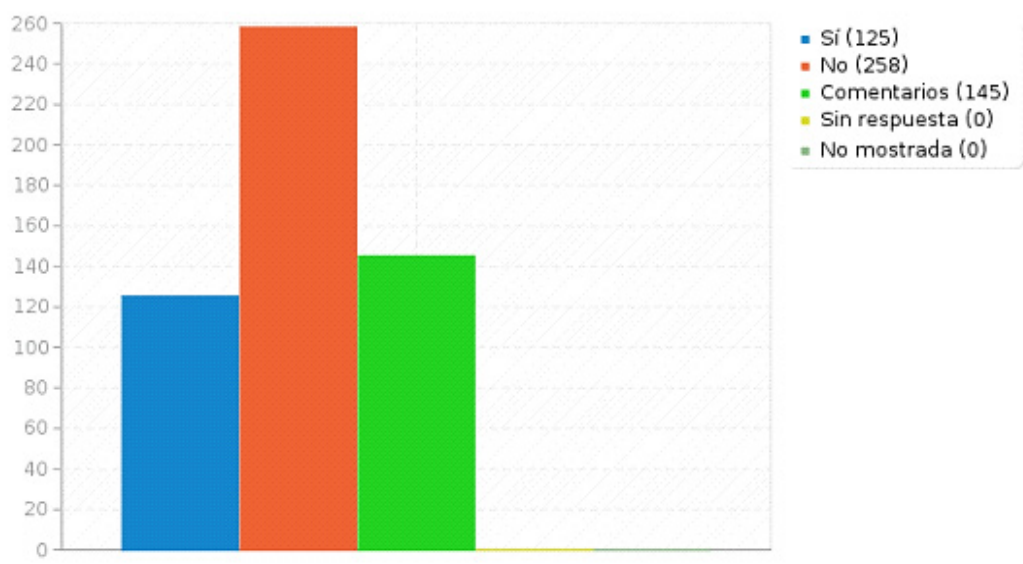

Figura 4. ¿Ha utilizado algún mecanismo de protección para reclamar sus derechos como desplazado?

construcción de una matriz de información categorizada por derechos reclamados, mecanismos de protección y políticas de atención, como se observa en la Tabla 1 y 2.

\section{Resultados de la investigación:}

De acuerdo con las respuestas brindadas por los encuestados, los resultados obtenidos de la investigación realizada son los siguientes:

- $\quad$ El $\mathbf{5 8 . 7 5 \% ~ d e ~ l o s ~ e n c u e s t a d o s ~ p e r t e n e c e n ~ a l ~}$ sexo femenino, lo que demuestra el alto índice de mujeres que se han visto obligadas a dejar sus hogares como consecuencia de una guerra en la cual se han visto inmersas. Las mujeres han padecido distintos hechos victimizantes como el asesinato de sus esposos, el reclutamiento forzado de sus hijos y hasta actos de violencia sexual, hechos que las ha llevado a desplazarse. Así, las mujeres son víctimas de diferentes delitos que las expone a un estado de fragilidad y de vulnerabilidad ante la sociedad de acogida; sociedad que muchas veces las discrimina y las rechaza dejándolas a merced de las inclemencias propias que genera el desplazamiento. Es por esto que la Corte Constitucional ha querido brindarles una especial protección cuando se encuentran en situación de desplazamiento (Carrascal, 2016). Nos referimos al Auto 092 del 2008, donde la Corte Constitucional hace 
Tabla 1.

Categorías de análisis de la información. Entrevistas Líderes de Víctimas.

\begin{tabular}{|c|c|c|}
\hline Categoria & Descripción & Subcategorias \\
\hline $\begin{array}{l}\text { Vulneración de } \\
\text { derechos }\end{array}$ & $\begin{array}{l}\text { Esta categoría se refiere } \\
\text { al desconocimiento de los } \\
\text { derechos fundamentales } \\
\text { de las víctimas del } \\
\text { desplazamiento forzado } \\
\text { interno como consecuencia } \\
\text { de dicho flagelo. }\end{array}$ & $\begin{array}{l}\text { - Derecho a la vivienda digna } \\
\text { - Derecho a la ayuda inmediata (albergue + alimentación) } \\
\text { - Derecho a la salud } \\
\text { - Derecho a la educación } \\
\text { - Derecho a una atención psicológica. }\end{array}$ \\
\hline $\begin{array}{l}\text { Protección de } \\
\text { derechos }\end{array}$ & $\begin{array}{l}\text { Esta categoría } \\
\text { hace referencia a } \\
\text { los mecanismos } \\
\text { jurídicos nacionales e } \\
\text { internacionales que utilizan } \\
\text { para buscar la garantía } \\
\text { de los derechos de las } \\
\text { personas desplazadas. }\end{array}$ & $\begin{array}{l}\text { - Recurso de reposición y de apelación, contra la Resolución de } \\
\text { la Unidad de víctimas que niega el reconocimiento como víctimas } \\
\text { del desplazamiento. } \\
\text { - Acción de Tutela } \\
\text { - Derecho de Petición } \\
\text { - Acción de Cumplimiento }\end{array}$ \\
\hline $\begin{array}{l}\text { Principales } \\
\text { Obstáculos } \\
\text { para el } \\
\text { reconocimiento } \\
\text { de derechos }\end{array}$ & $\begin{array}{l}\text { Esta categoría se refiere } \\
\text { a las diversas barreras } \\
\text { que deben superar los } \\
\text { desplazados para obtener } \\
\text { la garantía de sus derechos }\end{array}$ & $\begin{array}{l}\text { - Falta de capacitación de los funcionarios encargados de } \\
\text { atender a los desplazados. } \\
\text { - Falta de divulgación de los mecanismos de protección. } \\
\text { - Escaso compromiso institucional en la búsqueda de la verdad. } \\
\text { - Falta apoyo psicosocial } \\
\text { - Falta de un plan de contingencia adecuado a las necesidades } \\
\text { de las víctimas. } \\
\text { - Ausencia de proyectos de emprendimiento para que los } \\
\text { desplazados generen sus propios ingresos y, de esa manera, se } \\
\text { les garantice el derecho al trabajo. }\end{array}$ \\
\hline
\end{tabular}

Fuente: Elaboración propia a partir de los datos obtenidos de los instrumentos aplicados.

un análisis de la vulneración de derechos que se presenta cuando una mujer es desplazada, y además alerta sobre la necesidad que existe de protegerlas de una manera diferencial. La Corte requiere a las autoridades encargadas de atender a las mujeres desplazadas para que lo hagan a la inmediatez. En dicho Auto manifiesta: "Abstenerse de actuar resueltamente en este sentido conllevaría un desconocimiento del impacto diferencial del desplazamiento forzado sobre las mujeres, y contribuiría a su turno a reforzar la afectación desproporcionada que este fenómeno surte sobre sus derechos fundamentales" Corte Constitucional (Auto 092, 2008). De esta manera, a las mujeres desplazadas se les debe atender de una manera prioritaria porque no son solo víctimas del desplazamiento, sino que comoya mencionamos, han sido víctimas de otros delitos que las colocan en una situación de vulnerabilidad extrema que demanda una reacción inmediata y eficaz en la protección de sus derechos.
- El 29.77\% de los encuestado fueron desplazados de la región del Catatumbo en el año 2005. Las razones de ese alto porcentaje se deben a las operaciones militares del Bloque Catatumbo de las autodefensas que operaron en dicha zona hasta el año 2004, año en el que se desmovilizaron con ocasión a la expedición de la Ley de Justicia y Paz. Dicho bloque fue creado por Vicente y Carlos Castaño con el fin de combatir la insurgencia guerrillera que operaba en el departamento de Norte de Santander, eligiendo como comandante a Salvatore Mancuso. Este bloque tenía tres frentes: la Gabarra, el frente Tibú y frente fronterizo. Cada frente contaba con 200 integrantes, quienes cometieron diferentes delitos como masacres, narcotráfico, desplazamientos forzados, homicidios selectivos, despojo de ganado y bienes. La arremetida paramilitar en la zona tuvo un gran impacto en la población catatumbera, ya que por años han sido estigmatizados como pertenecientes o simpatizantes de grupos guerrilleros. Las diferentes incur- 
Tabla 2.

Categorías de análisis de la información. Entrevistas Autoridades Locales

\begin{tabular}{|c|c|c|}
\hline Categoria & Descripción & Subcategorias \\
\hline $\begin{array}{l}\text { Derechos } \\
\text { Reclamados }\end{array}$ & $\begin{array}{l}\text { Esta categoría se refiere a los } \\
\text { derechos que reclaman las } \\
\text { víctimas del desplazamiento } \\
\text { cuando acuden a las oficinas } \\
\text { encargadas de atenderlos. }\end{array}$ & $\begin{array}{l}\text { - Derecho a la alimentación } \\
\text { - Derecho a la vivienda } \\
\text { - Derecho a la educación } \\
\text { - Derecho a la seguridad (protección a líderes) }\end{array}$ \\
\hline $\begin{array}{l}\text { Mecanismos de } \\
\text { Protección }\end{array}$ & $\begin{array}{l}\text { Esta categoría hace referencia } \\
\text { a los instrumentos jurídicos } \\
\text { utilizados por los funcionarios } \\
\text { encargados de propender por } \\
\text { la garantía de los derechos de } \\
\text { los desplazados. }\end{array}$ & $\begin{array}{l}\text { - Derecho de petición } \\
\text { - Acción de tutela } \\
\text { - Requerimientos interinstitucionales } \\
\text { - Recursos de reposición y de apelación (ante la Unidad de } \\
\text { Víctimas) }\end{array}$ \\
\hline $\begin{array}{l}\text { Políticas de } \\
\text { Atención }\end{array}$ & $\begin{array}{l}\text { Esta categoría se refiere a } \\
\text { la respuesta institucional } \\
\text { ofrecida para contrarrestar } \\
\text { los efectos que genera el } \\
\text { desplazamiento forzado } \\
\text { interno en sus víctimas. }\end{array}$ & $\begin{array}{l}\text { - Asesorías especializadas sobre sus derechos } \\
\text { - Proyección de Recursos } \\
\text { - Proyección de Acciones constitucionales } \\
\text { - Acompañamiento institucional en situaciones de emergencia } \\
\text { humanitaria } \\
\text { - Apoyo Económico } \\
\text { - Apoyo psicológico }\end{array}$ \\
\hline $\begin{array}{l}\text { Obstáculos } \\
\text { en la } \\
\text { implementación } \\
\text { de las políticas } \\
\text { de atención }\end{array}$ & $\begin{array}{l}\text { Esta categoria hace referencia } \\
\text { a las complicaciones que se les } \\
\text { presentan a las autoridades } \\
\text { locales a la hora de atender las } \\
\text { necesidades de las víctimas del } \\
\text { desplazamiento forzado. }\end{array}$ & $\begin{array}{l}\text { - Falta de recursos económicos } \\
\text { - Falta de recursos humanos } \\
\text { - Falencias de la Ley } 1448 \text { del } 2011 \text { (requiere de } \\
\text { modificaciones) } \\
\text { - Falta de priorización de recursos, atendiendo las categorías } \\
\text { de los municipios receptores de población desplazada. } \\
\text { - Falta de capacitación a la población desplazada. }\end{array}$ \\
\hline
\end{tabular}

Fuente: Elaboración propia a partir de los datos obtenidos de los instrumentos aplicados.

siones de dicho bloque, a través de asesinatos, secuestros, violencia sexual, reclutamiento de menores, y enfrentamientos con los grupos guerrilleros, incrementó la violencia en la región, lo que llevó a miles de campesinos a desplazarse durante dicho año. Además de lo anterior, una vez desmovilizado dicho bloque, los grupos guerrilleros que operan en la zona como el ELN, las FARC y el EPL, comenzaron una guerra por el control territorial que dejaron los paramilitares, exponiendo a la población civil a las inclemencias de una guerra ajena a sus intereses que pretendía controlar las actividades delictivas que les permitía dicha región por su estratégica ubicación y por el clima tropical que favorece el cultivo de coca. Durante esa época, la población campesina se vio obligada a dejar sus hogares huyendo de dicho conflicto, buscando tranquilidad y bienestar para sus familias. Cabe mencionar que el año 2018 ha sido un periodo de violencia generalizada en la región del Catatumbo que ha generado miles de desplazamientos como en aquella época del 2005.
- El 18.54\% de los encuestados se desplazaron de la zona urbana y rural del municipio de Convención hacia el municipio de Ocaña, convirtiéndose en el principal expulsor de población entre los años 2005 y 2017. La parte rural de dicho municipio se compone de 13 corregimientos y 80 veredas, cuya ubicación inmersa en las zonas montañosas del Catatumbo, hace que sean apetecidas por los grupos armados ilegales para adelantar sus operaciones delictivas. Esto genera una lucha armada entre ellos, que no aplica el principio de distinción del Derecho Internacional Humanitario, al contrario, las personas más afectadas son la población civil campesina. Dentro de esto debemos mencionar que el posicionamiento paramilitar entre 1999 y 2003 generó miles de desplazamientos en el municipio de Convención. En el mismo sentido, en el informe presentado por el Centro de Memoria Histórica sobre el Catatumbo, los investigadores aseguraron lo siguiente: 
Luego de su arremetida, los paras permanecieron en Convención alrededor de tres años y medio. Después de su derrota militar en Honduras, controlaron la cabecera municipal de Convención, por ser un punto estratégico (...) En la cabecera municipal los paramilitares vestían de civil, pero armados, vivian en casas de las que habían expulsado a sus residentes y establecieron control absoluto de la población. (CNMH, 2018, p.399)

- Hoy en día, los desplazamientos forzados siguen presentándose en dicho municipio como resultado de la guerra entre guerrillas (ELN y $\mathrm{EPL}$ ) que se ha agudizado a lo largo de este 2018, disputándose el control territorial como objetivo clave para mantener el negocio del narcotráfico.

- $\quad$ El 56.66\% de los encuestados eligió el derecho a la vivienda como el derecho que más se vulnera a la población desplazada. La población víctima del Catatumbo considera como esencial la garantía de su derecho a una vivienda digna; esto como pilar fundamental para iniciar la reconstrucción de sus proyectos de vida interrumpidos. Lo anterior, teniendo en cuenta que el retorno como solución a su situación de desplazamiento no es una opción viable ante la ola de violencia que se vive en la zona y que se ha mantenido a lo largo del 2018 y 2019 como consecuencia del conflicto entre los grupos al margen de la ley por la disputa del territorio Catatumbero.

Dicho derecho se encuentra consagrado en nuestra Constitución dentro de los derechos de segunda generación, denominados Derechos Económicos Sociales y Culturales: "Todos los colombianos tienen derecho a vivienda digna." (Const., 1991, art. 51). El Estado fijará las condiciones necesarias para hacer efectivo este derecho y promoverá planes de vivienda de interés social, sistemas adecuados de financiación a largo plazo y formas asociativas de ejecución de estos programas de vivienda. No obstante, si bien existe este mandato constitucional, cuando la población se ve obligada a abandonar su lugar de residencia se configura una vulneración latente de dicho derecho constitucional. De esa manera, lo interpretó el legislador cuando expidió la Ley 1448 del 2011, en la cual se consagra dentro de los derechos de la población desplazada, el derecho a una reparación integral. Dicho derecho supone la posibilidad de obtener medidas de reparación como la restitución de sus tierras cuando las condiciones de seguridad así lo permitan. Es decir, la Ley pretende garantizar a los desplazados su derecho a la vivienda a través del retorno a sus hogares, o de lo contrario reubicarlos en viviendas que se encuentren en condiciones dignas. De esta manera, el Estado ha pretendido garantizar dicho derecho que alegan las víctimas del desplazamiento a través de programas de vivienda tanto a nivel municipal como nacional que permita a los desplazados gozar de su propia vivienda. A nivel local, las víctimas del desplazamiento alegan más claridad en la selección de los beneficiarios de dichos programas, ya que han limitado el acceso a los mismos por parte del ente territorial. Sin embargo, cabe anotar que el municipio de Ocaña maneja una cobertura limitada en cuanto a los programas de vivienda de interés social, lo que dificulta el acceso a los mismos, tanto a las personas que se encuentran en estado de pobreza extrema como a las personas que llegan en condición de desplazamiento.

- De ese $\mathbf{3 2 , 6 4 \%}$ que contestó de manera afirmativa haber utilizado un mecanismo de protección, 100 personas manifestaron cuál fue el utilizado:

\begin{tabular}{ll}
\hline Mecanismo & $\begin{array}{l}\text { Cantidad de } \\
\text { Encuestados }\end{array}$ \\
\hline 1. Derecho de Petición & 47 \\
\hline 2. Acción de Tutela & 44 \\
\hline 3. Denuncia Penal & 2 \\
\hline $\begin{array}{l}\text { 4. Derecho de petición + Acción de } \\
\text { Tutela }\end{array}$ & 5 \\
\hline 5. Denuncia Penal + Acción de Tutela & 1 \\
\hline $\begin{array}{l}\text { 6. Derecho de petición + Acción de } \\
\text { Tutela + Denuncia Penal }\end{array}$ & 1 \\
\hline
\end{tabular}

De esta manera, vemos cómo los mecanismos constitucionales de protección de derechos (derecho de petición art. 23 y la acción de tutela art. 86), son los más utilizados por la población desplazada para reclamar sus derechos. Esto debido a la informalidad y a la inmediatez en su resolución que les permite obtener una pronta respuesta a su reclamación. 


\section{Conclusiones}

\section{Precaria garantia de sus derechos ante la continuidad de desplazamientos}

Cuando el Estado colombiano firmó los acuerdos de paz con uno de los grupos guerrilleros actores del conflicto armado interno se generó una expectativa de tranquilidad y de paz, que poco a poco fue siendo desvirtuada en la región del Catatumbo, quienes aún no conocen los efectos de la tan anhelada Paz. Esta zona ha sido presa de un conflicto donde operan todos los actores armados: ELN, EPL, AUTODEFENSAS, las llamadas disidencias de las FARC y la Fuerza Pública. Los constantes enfrentamientos entre estos ha provocado el desplazamiento masivo de miles de Catatumberos hacia el municipio de Ocaña en búsqueda de una atención estatal efectiva que les permita volver a gozar de sus derechos fundamentales.

A lo largo del 2018, los grupos guerrilleros del EPL y del ELN han mantenido una guerra por el control territorial de esta región ante los privilegios climáticos que ofrece para la producción de la coca y su ubicación estratégica que les permite su comercialización. Este fenómeno social parece no tener fin en esta zona del país, controlada por estos grupos guerrilleros. Mientras la población desplazada crece y se acordona en el municipio de Ocaña, la garantía de sus derechos cada vez se ve más imposible de lograr. Este municipio de acogida mantiene problemas sociales serios, como altos indices de pobreza, limitaciones en la cobertura de los servicios públicos domiciliarios, precaria atención en el sistema de salud, desempleo y la proliferación de sustancias psicoactivas en sus instituciones educativas. Esto supone que las necesidades básicas de los Ocañeros aún se encuentran insatisfechas en un gran número de su población. Lo que impide una respuesta local efectiva para aquellos otros que llegan reclamando lo mismo, con un componente adicional de ser víctimas de los conflictos como desplazados, acreedores de una atención con enfoque diferencial (Art. 13 de la Ley 1448 del 2011).

En el desarrollo de la investigación evidenciamos que la población desplazada reclama del Municipio de Ocaña una garantía efectiva de su derecho a una vivienda digna. Derecho que aún sigue siendo desconocido a miles de habitantes de este municipio, quienes lo reclaman de igual forma, pero su condición de "no desplazado" les impide estar priorizados en los programas de vivienda que ofrece su municipio. Esta problemática impide una garantía efectiva de los derechos vulnerados con ocasión al desplazamiento, puesto que llegan a un lugar donde sus habitantes se encuentran a la espera de lo mismo.

\section{Desconocimiento de sus derechos y de los mecanismos para protegerlos}

La población desplazada encuestada evidenció que el Estado no ha realizado la labor de promoción y divulgación de sus derechos, como tampoco de la forma como pueden reclamarlos. Muchos de ellos desconocen las ayudas a las cuales tienen derecho, los derechos constitucionales que les son vulnerados con ocasión al desplazamiento y los mecanismos jurídicos para reclamarlos. No obstante, de acuerdo con las entrevistas realizadas, algunas autoridades desarrollan actividades de capacitación sobre este grupo poblacional, sobre sus derechos, pero resultan escasas ante el aumento de desplazados de la región del Catatumbo que impiden acceder a cada uno de ellos. Debido a ello, es indispensable la labor de sus líderes, quienes realizan una labor replicadora, en la comunidad que representan, de las capacitaciones que reciben por parte de las autoridades e instituciones educativas. Sin embargo, la actualización de las mismas y las difíciles condiciones de inseguridad impide muchas veces que las autoridades intervengan en terreno con una misión educativa sobre sus derechos. Los líderes representan la vocería de una comunidad de desplazados, la esperanza de ser escuchados y la posibilidad de conocer a través de ellos ese mundo jurídico que existe para reclamar la garantía de sus derechos vulnerados.

\section{Limitaciones Institucionales para la Atención.}

La respuesta institucional a la crisis humanitaria que genera el DFI en la zona del Catatumbo parece generosa. Sin embargo, las consecuencias sociales que se producen en el municipio de Ocaña no están contrarrestadas por parte del ente territorial. La llegada masiva de desplazados al municipio ha hecho imposible una respuesta local efectiva en la garantía de sus derechos. La capacidad institucional es limitada ante la proliferación de 
necesidades básicas insatisfechas de las víctimas del DFI, quienes esperan que los mandatos legales y constitucionales se cumplan por parte de las autoridades locales. Es decir, las herramientas legales y jurídicas existen para el desarrollo de las funciones estatales en favor de la población desplazada. No obstante, esas políticas públicas encuentran tropiezos en su aplicación cuando las realidades sociales superan las expectativas iniciales al momento de su definición.

El Estado colombiano ha ofrecido un marco legal específico para la atención de las necesidades de la población desplazada, (ley 387 de 1997 y Ley 1448 del 2011). Dichas normas fueron creadas bajo el diseño de políticas públicas de atención como ruta a seguir por parte de las entidades que componen el sistema nacional de atención a las víctimas. Sin embargo, la población desplazada reclama una respuesta inmediata a sus necesidades, que los entes locales no están en la capacidad de atender. Si bien existe un marco jurídico, su aplicación resulta impetuosa ante la masividad que supone el desplazamiento forzado interno en la región del Catatumbo, y que como lo mencionamos continúa generándose sin posibilidad cercana de que se detengan.

\section{Desplazamientos Permanentes}

La situación de violencia en la región del Catatumbo aún se mantiene. Los desplazamientos forzados de dicha zona expulsora han aumentado a lo largo del 2018 como consecuencia de los enfrentamientos entre los grupos guerrilleros ELN y EPL. Las consecuencias sociales que ello genera para el municipio de Ocaña han aumentado el índice de pobreza extrema, ante la escasa respuesta institucional frente a los derechos que reclaman. Esto, a pesar de la existencia de un marco legal a favor de dicha población, pero que se encuentra insuficiente cuando las autoridades se enfrentan a la realidad humanitaria que genera el desplazamiento en las víctimas del Catatumbo. Además de lo anterior, las autoridades entrevistadas coincidieron en la necesidad de aumentar los recursos económicos y humanos para garantizar los derechos de la población desplazada. Para ello, es necesario que la asignación de recursos se realice teniendo en cuenta la categorización de los municipios y las dinámicas de estos, ya que las autoridades locales de aquellos municipios que se reconocen como principales receptores de víctimas del desplazamiento forzado, como Ocaña, no cuentan con los recursos suficientes para atender las necesidades de estas. De allí nace la inconformidad de las víctimas encuestadas, quienes pretenden la garantía de sus derechos constitucionales, especialmente su derecho a una vivienda digna, el cual resulta difícil de reconocer, puesto que las autoridades locales se encuentran con límites presupuestales para garantizarlo. La respuesta estatal frente a las necesidades que se desprenden del flagelo del desplazamiento no están diseñadas cuando se presentan estos de manera masiva. Municipios receptores como Ocaña, no tienen la capacidad humana ni presupuestaria para aplicar de manera efectiva las ayudas contempladas en la Ley 1448 del 2011, de las cuales son acreedoras las víctimas del desplazamiento. Finalmente, debemos precisar que cuando se presenta el desplazamiento forzado interno en la región del municipio se produce una vulneración masiva de derechos constitucionales y legales, que las autoridades del municipio de Ocaña, como principal receptor de estas, debe atender y, asimismo, garantizar. Sin embargo, como ya se mencionó, para las víctimas no es suficiente la existencia de un mandato legal que reconozca sus derechos, sino que se deben proporcionar los medios para que el cumplimiento de estos sea efectivo por parte de las autoridades locales.

\section{Referencias}

Abrisketa, J. (2009). La Población Internamente Desplazada en Colombia: claves para interpretar la regulación internacional. Revista Electrónica de Estudios Internacionales. Disponible en: https://revistas.unc.edu.ar, 18, 18, p 5.

Carrascal, A. M. (2016). El Fenómeno del Desplazamiento Forzado interno desde el Derecho Internacional: El Caso Colombiano. Madrid, España (Tesis de Doctorado) Universidad Carlos III de Madrid, Madrid.

Carrascal, A. M. (2018) El Desplazamiento Forzado Interno en la Región del Catatumbo

Marco Jurídico Nacional e Internacional de Protección de sus Derechos. (Proyecto de investigación) Universidad Francisco de Paula Santander Ocaña, p11.

Caso Masacre de Mapiripán (Corte Interamericana de Derechos Humanos 15 de septiembre de 2015).

Ceballos, M. A. (2013). El desplazamiento forzado en Colombia y su ardua reparación. Araucaria. Re- 
vista Iberoamericana de Filosofía, Política y Humanidades, 29, P 169-188

Centro Nacional de Memoria Histórica (2015) Una nación desplazada: Informe Nacional del Desplazamiento Forzado en Colombia, Bogotá, $\mathrm{CNMH}$ - UARIV

Centro Nacional de Memoria Histórica (2018), Catatumbo: Memorias de Vida y Dignidad, Bogotá, CNHM-UARIV. P 399.

Cletus, G. (2 ed) (2000). Pueblos indígenas y derechos constitucionales en américa latina: un panorama. México. Editorial Abya-Yala.

Colombia, C. d. (28 de mayo de 2017). Decreto 893. Bogotá. Obtenido de: www.acnur.org

Corporación Colectivo de Abogados Luis Carlos Pérez. (2012). Catatumbo territorio de paz. Bucaramanga.

Jiménez \& Soledad. (2007). Territorio, conflicto y migraciones en el contexto colombiano. Cuadernos Geográficos, 184-194.

Londoño, L. F. (2007). Derecho Internacional Público. Bogotá: Pontificia Universidad Javeriana.
Martin, Rodríguez \& Guevara. (2004). (1 ed.) Derecho Internacional de los Derechos Humanos. México. Universidad Iberoamericana.

ONU. (11 de marzo de 2002). Integration of the human rights of women and the gender perspective, violence against women. Mission to Colombia. Obtenido de Annual reports: www.ohchr.org

Oraa \& Gómez. (2002). La Declaración Universal de Derechos Humanos. Bilbao: Universidad de Deusto.

Remon, F. Q. (2009). Evolución Normativa de la Protección de los Derechos Humanos con el Sistema Interamericano. Revista Electrónica Iberoamericana. Disponible en: http://www.urjc.es/ceib/, 3. P 155

Sacipa, P. (2001). Desplazamiento Forzado y Política de Erradicación de Cultivos Ilícitos. Revista Electrónica de Geografía y Ciencias Sociales, 39.

Vidal, R. (2007). (1 ed.) Derecho global y desplazamiento interno: creación, uso y desaparición del desplazamiento forzado por la violencia en el derecho contemporáneo. Bogotá, Colombia. Pontificia Universidad Javeriana.. 